\title{
Low Cost Technology Developed and Used for Screening and Selecting Few Field and Vegetable Crops for Tolerance to Few Abiotic Stresses
}

\author{
Ratikanta Maiti ${ }^{*}$, Humberto Gonzalez Rodriguez ${ }^{2}$, P. Satya ${ }^{3}$, and P. V. Sagar ${ }^{4}$ \\ ${ }^{1}$ Hony and Retired Professor, Universidad de las Americas (UDLA), Puebla, Mexico (67700), Mexico \\ ${ }^{1}$ Universidad Autonoma de Nuevo Leon, Facultad de Ciencias Forestales, Carr. Nac. No. 85, km 145, Linares, Nuevo Leon, \\ ${ }^{4}$ Division of crop Improvement, CRIJAF, Barrackpore, West Bengal (700 120), India; ${ }^{5}$ Vibha Seeds, Hyderabad, Andhra Pradesh, India
}

\section{Article History}

Manuscript No. AR662a

Received in $24^{\text {th }}$ February, 2014

Received in revised form $4^{\text {th }}$ March, 2014

Accepted in final form $24^{\text {th }}$ May, 2014

\section{Correspondence to}

*E-mail: ratikanta.maiti@gmail.com

\section{Keywords}

Abiotic stress, tolerance, low cost technology

\begin{abstract}
Stress is a global threat in achieving potential crop yield. Abiotic stresses like drought, salinity, heat stress and other abiotic stresses associated several associated with ever increasing human populations affect crop productivity drastically under sustainable agriculture in the farmers fields. Though significant research activities have been taken place to address these problems with respect to the mechanism of resistance and crop improvement but little progress has been achieved. Here, several low cost technologies have been developed for screening crop cultivars for few abiotic stresses viz. screening for tolerance to salinity, drought, heat stress, flooding and cold stress. Seedling Emergence percentage, tap root length and number of lateral roots was considered important parameters for selection of salinity tolerant hybrids in cotton. Salinity tolerant genotypes showed high emergence percentage under saline concentration compared to remaining genotypes. These hybrids produced more number of profuse lateral roots and long tap roots in saline concentration compared to control for osmotic adjustment and increase in tap root length. $90 \%$ of seeding survival may be selected for heat tolerant at seedling stage. These hybrids may be recommended for growing under heat and drought stress prone areas for better adaptation. Hybrids with thick leaves, stout petiole, good survival under drought \& recovery from stress are considered for selecting drought resistant hybrids in castor
\end{abstract}

\section{Introduction}

Global warming, drought, salinity, heat stress and other abiotic stresses associated several associated with ever increasing human populations affect crop productivity drastically under sustainable agriculture in the farmers fields. Though significant research activities to address these problems with respect to the mechanism of resistance and crop improvement but little progress has been achieved. In this direction several low cost technologies have been developed for screening crop cultivars for few abiotic stresses viz. screening for salinity tolerance, screening for drought tolerance, screening for heat stress tolerance, flooding tolerance and cold stress tolerance. In the following section, some examples are cited crop wise how the low cost screening technologies can be used for identification of tolerant genotypes within a short period. More details can be obtained from thepublications mentioned in the reference section.

\section{Study on Stress Tolerance}

Technology development for various abiotic stress tolerance of different crops are cited below:

\subsection{Salinity tolerance}

\subsubsection{Screening of cotton varieties and hybrids for salinity} tolerance at seedling stage

A study was undertaken to evaluate salinity tolerance of cotton varieties and hybrids for salinity tolerance at different levels (0.15 and $0.2 \mathrm{M} \mathrm{NaCl})$.

\subsubsection{Materials and methods}

Two experiments were conducted, i) Mass scale screening of all the entries at $0.15 \mathrm{M} \mathrm{NaCl}\left(\mathrm{EC}=13.6 \mathrm{dS} \mathrm{m}^{-1}\right)$, where total 32 entries of cotton which include varieties, hybrids and hybrid checks, where screened for salinity tolerance at $0.15 \mathrm{M} \mathrm{NaCl}$ using by semi-hydroponic technique; and screening of selected entries at $0.15 \mathrm{M} \mathrm{NaCl}\left(\mathrm{EC}=13.6 \mathrm{dS} \mathrm{m} \mathrm{m}^{-1}\right)$ and $0.2 \mathrm{M} \mathrm{NaCl}$ 
$\left(\mathrm{EC}=\mathrm{dS} \mathrm{m}^{-1}\right)$, where selected nine entries and some susceptible entries were screened at $0.15 \mathrm{M} \mathrm{NaCl}\left(\mathrm{EC}=13.6 \mathrm{dS} \mathrm{m}^{-1}\right)$ and 0.2 $\mathrm{M} \mathrm{NaCl}\left(\mathrm{EC}=18 \mathrm{dS} \mathrm{m}^{-1}\right)$ along with control (Figure 1-4).

\subsubsection{Results and discussion}

- Two highly salinity tolerant hybrids (at $0.2 \mathrm{M} \mathrm{NaCl}$ ) were obtained above $70 \%$ seedling emergence at $0.2 \mathrm{M} \mathrm{NaCl}$ $\left(E C=18 \mathrm{dS} \mathrm{m}^{-1}\right)-2$ hybrids and seven moderately salinity tolerant Varieties/ hybrids (at $0.15 \mathrm{M} \mathrm{NaCl}$ ): $\geq 70 \%$ seedling emergence at $0.15 \mathrm{M} \mathrm{NaCl}\left(\mathrm{EC}=13.6 \mathrm{dS} \mathrm{m}^{-1}\right)$ - were selected.

- Emergence percentage, root length was considered important parameters for selection of salinity tolerant hybrids in cotton. Seedling emergence (\%) was positively correlated with shoot length $(\mathrm{r}=0.564$ at $p<0.01)$, tap root length $(0.683$ at $p<0.01)$ and with number of lateral roots $(0.418$ at $p<0.01)$.

- Salinity tolerant hybrids showed high emergence percentage in saline concentration compared to remaining hybrids. These hybrids produced more number of profuse lateral roots and long tap roots in saline concentration compared to control for osmotic adjustment.

- With an increase in salt concentration there was an increase in root elongation and number of lateral roots in salt tolerant lines, but not in in the susceptible ones.

- This study supports the earlier findings in the aspect of root length and emergence percentage in saline concentrations. Therefore, these hybrids can be recommended effectively for growing in saline prone areas

\subsubsection{Conclusion}

Seedling emergence percentage, tap root length and number of lateral roots was considered important parameters for selection of salinity tolerant hybrids in cotton. Salinity tolerant hybrids showed high emergence percentage in saline concentration compared to remaining hybrids. These hybrids produced more number of profuse lateral roots and long tap roots in saline concentration compared to control for osmotic adjustment and increase in tap root length. This study supports the earlier findings in the aspect of root length and emergence percentage in saline concentrations. Therefore these hybrids can be recommended effectively for growing in saline prone areas.

\subsubsection{Screening of sunflower hybrids for salinity tolerance}

\subsubsection{Materials and methods}

Fifteen sunflower hybrids are screened for salinity tolerance at $0.15 \mathrm{M} \mathrm{NaCl}$ (13.6 EC) (selected earlier as max, salinity stress) by using semi- hydroponic technique. Seedling emergence was taken daily up to termination of the experiment. Calculated seedling emergence percentage, shoot length and root length was recorded for 12 days old seedlings (Figure 5-7).

\subsubsection{Results and Discussion}

- Lot of variations observed among these hybrids in the aspect of emergence \%, shoot length and root length. High emergence (\%) and increased root length under saline condition is an important selection criteria for salinity tolerance in Sunflower.

- Total 5 hybrids are selected for salinity tolerance. It is noted that root length increased at high salinitry stress in salinity tolerant hybrids while it decreased in the susceptible ones.

- Few highly tolerant hybrids at $0.15 \mathrm{M} \mathrm{NaCl}$ (13.6 EC) (70\% emergence and above) were selected for further confirmation.

- Emergence \% is decreased with increase in salinity concentration. Tolerant hybrids shown negligible $\%$ of reduction in emergence but susceptible hybrids has shown drastic reduction. These hybrids can tolerate up to $0.15 \mathrm{M}$ $\mathrm{NaCl}$ concentration.

- It was noted that root length increased at high salinitry stress in salinity tolerant hybrids while it decreased in the susceptible ones.

- Shoot length decreased with increase in salinity concentration. Root length increased in tolerant hybrids under saline conditions compared with control.

\subsubsection{Conclusion}

High emergence (\%) and increased root length under saline condition is an important selection criteria for salinity tolerance in Sunflower.

\subsubsection{Screening of pearl millet lines for salinity tolerance}

\subsubsection{Materials and methods}

Screening was conducted for 20 pearl millet lines (parents) for salinity tolerance $\left(0.15 \mathrm{M} \mathrm{NaCl} \mathrm{EC}=13 \mathrm{dS} \mathrm{m}^{-1}\right)$ at seedling stage along with control $\left(\mathrm{EC}=0 \mathrm{dS} \mathrm{m^{-1 }}\right)$. Data were taken on average seedling emergence (\%), speed of emergence, seedling vigour index, shoot length $(\mathrm{cm})$, root length $(\mathrm{cm})$ and number of adventitious roots of ten seedlings on $15^{\text {th }}$ day after emergence (Figure 8-9).

\subsubsection{Results and discussion}

- High variations were observed among the genotypes with respect to seedling mergence, speed of emergence, shoot length and root length under $0.15 \mathrm{M} \mathrm{NaCl}$.

- Emergence percentage, root length was considered as important parameters for selection of salinity tolerant lines in Bajra. Salinity tolerant genotypes showed high emergence percentage under saline concentration compared to remaining genotypes. These genotypes produced increased root length and more number of adventitious roots in saline concentration compared to control for osmotic adjustment. 
- Under saline condition, seedling emergence (\%) was positively correlate with speed of emergence $(\mathrm{r}=0.601$ at 0.01 level) but under control this is not observed

- Under saline condition, Seedling emergence (\%) was positively correlate with number of adventitious roots $(r=0.507$ significant at 0.01 level), but under control condition correlation is significant at the 0.05 level $(r=0.402)$. With an increase in saline concentration, there was an increase in root length in salt tolerant lines, but the reverse was in the susceptible ones.

- Under saline condition, shoot length was positively correlated with root length Correlation is significant at the 0.01 level $(\mathrm{r}=0.672)$, but under control condition, correlation is significant at the 0.01 level $(\mathrm{r}=0.360)$.

\subsubsection{Conclusion}

From this study, emergence percentage, root length and number of adventitious roots was considered as important parameters for selection of salinity tolerant lines in Bajra. Salinity tolerant genotypes showed high emergence percentage under saline concentration compared to remaining genotypes. These genotypes produced increased root length and more number of adventitious roots in saline concentration compared to control for osmotic adjustment. Few lines wreslectedat 0.15 $\mathrm{M} \mathrm{NaCl}\left(\mathrm{EC}=13.6 \mathrm{dS} \mathrm{m}^{-1}\right)$ (seedling emergence in $0.15 \mathrm{M}$ $\mathrm{NaCl}$ is $\geq 70 \%$ )

This study supports the earlier findings in the aspect of greater root length and emergence percentage in saline concentrations. Therefore these genotypes can be recommended effectively for developing salinity tolerant hybrids. It is suggested that the breeder should combine the highly salt tolerant parenys to make hybrids expecting high heterosis.

\subsubsection{Screening of nine maize hybrids and their parents for salinity tolerance}

\subsubsection{Materials and methods}

Thirty nine maize genotypes were screened for salinity tolerance at seedling stage by using semi-hydroponic technique (Number of treatments $=2(1=$ control, $2=0.2 \mathrm{M} \mathrm{NaCl}$. EC $=18 \mathrm{dS}$ $\mathrm{m}^{-1}$ ), number of replications for each treatment $=2$ ). Experiment was terminated at 16 days from the date of sowing and observed seedling growth parameters under control and saline conditions. Recorded emergence (\%), shoot length, root length, number of adventitious roots, seedling vigour index, shoot dry weight and root dry weight were taken (Figure 10-11).

\subsubsection{Results and discussion}

It was observed that tolerant genotypes showed high seedling emergence, high seedling vigour, and high seminal root length, High seminal root length and more number of adventitious roots function as osmotic adjustment.

\subsection{Emergence (\%)}

Salinity affects the emergence (\%) at greater level compared to remaining seedling parameters. It is observed that salinity concentration reduced the seedling emergence (\%).

\subsection{Shoot length}

It is observed that high salinity concentration decreases the shoot length. All the hybrids have shown decreased shoot length at $0.2 \mathrm{M} \mathrm{NaCl}$.

\subsection{Seminal root length}

Salinity tolerant genotypes shown high increased root length under saline concentration for osmotic adjustment compared other lines. Root length under saline condition was correlated with seedling emergence $(\mathrm{r}=0.45)$ at the 0.01 level.

\subsection{Number of adventitious roots}

Salinity stress reduced number of adventitious roots. But tolerant lines produced more number of adventitious root compared to susceptible lines under saline condition. Emergence (\%) is positively correlated with number of adventitious roots $(\mathrm{r}=0.587)$ at 0.01 level.

\subsection{Seedling vigour index}

Seedling vigour is highly correlated with seedling emergence $(\mathrm{r}=0.952)$ at the level of 0.01 under $0.2 \mathrm{M} \mathrm{Nacl}$. Salinity stress reduced speed of emergence, mesocotyl length and coleoptiles length in all the genotypes. Seedling emergence (\%) was positively correlated with seedling vigour index, seminal root length, No. of adventitious roots, coleoptile length, shoot length under 0.2 M Nacl. Selected Salinity Tolerant lines showing 80$100 \%$ of emergence and good seedling vigour at $0.2 \mathrm{M} \mathrm{NaCl}$ $\left(\mathrm{EC}=18 \mathrm{dS} \mathrm{m}^{-1}\right)$. List is tabulated below:

Higly salinity tolerant maize hybrids/parents showed high seedling emergence, high seedling vigour and high root vigour (on the basis of long seminal roots and greater number of adventitious roots. It is recommended that the A lines (female) may be recommended to increase salinity tolerance of poor and susceptible hybrids utilizing efficient breeding techniques.

\subsubsection{Conclusion}

High emergence (\%), profuse root system, high seedling vigour is considered for salinity tolerance in maize. Seedling vigour especially root vigour is very important parameter for selecting hybrids/ parents salinity tolerance. Salinity tolerant genotypes produced more number of profuse adventitious roots under saline condition for osmotic adjustment. Genotypes having high emergence (\%) also shown good root vigour in most of the cases. Overall it is observed that many salinity tolerant genotypes shown good seedling vigour under control and saline conditions.

\subsubsection{Screening of rice varieties for salinity tolerance}




\subsubsection{Materials and methods}

Twenty sevenrice varieties (including 7 checks) were screened for salinity tolerance at $0.2 \mathrm{M} \mathrm{NaCl}\left(\mathrm{EC}=18.1 \mathrm{dS} \mathrm{m}^{-1}\right)$. Two treatments are used in this study i.e., control and $0.2 \mathrm{M} \mathrm{NaCl}$. Three replication and 20 seeds per each replication are used for each treatment. Data was taken at 15 days after sowing (Figure 12).

\subsubsection{Results and discussion}

\subsection{Emergence (\%)}

Salinity stress considerably reduced seedling emergence (\%). Emergence at $0.2 \mathrm{M} \mathrm{NaCl}$ ranging from $10 \%$ to $92.5 \%$.

\subsection{Root length}

Seminal root length was reduced in all the varieties due to effect of salinity. But the morphology of root system shows variation. Under saline condition tolerant varieties expressed high number of profuse adventitious roots compared to susceptible varieties.

\subsubsection{Conclusion}

Maize genotypes showed large variability in tolerance to salinity/ with an increase in salt concentration tolerant genotypes showed an increase in root length, while the reverse is the case in the case of susceptible one.

\subsection{Heat tolerance}

2.2.1. Screening of 39 maize lines (hybrids and parents) for heat tolerance at seedling stage

\subsubsection{Materials and methods}

Thirty ninemaize lines (hybrids and parents) are screened (Mass scale screening) for heat stress tolerance at early seedling stage. Three replications are kept for each hybrid. 4 seedlings are maintained for each replication. Seedlings are grown normally up to 25 days, at $45-47^{\circ} \mathrm{C}$ temperature (during this experiment maximum recorded temperature was $45-47^{0}$ $\mathrm{C}$ temperature). This condition offers scope for selecting for heat stress tolerance at seedling stage which gives maximum stress on seedling survival, establishment and growth (Figure 13-14).

\subsubsection{Results and discussion}

- Percentage of seedling survival under heat stress condition has been taken into consideration for selecting heat tolerant lines.

- Lines showing $90 \%$ of seeding survival are selected for Heat tolerant at seedling stage. 4 lines are selected for heat tolerance.

- There is large genotypic variation is observed in seedling survival ranging from 0 to $90 \%$ exposed to heat stress.

- Few linesare showing 90\% of seedling survival after completion of 25 days under $45-47^{\circ} \mathrm{C}$ temperature.

\subsubsection{Conclusion}

Percentage of seedling survival under stress condition has taken into consideration for selecting heat lines showing $90 \%$ of seeding survival is selected for Heat tolerant at seedling stage. Four lines were selected for heat tolerance.

\subsubsection{Screening of tomato hybrids for heat tolerance at} seedling stage and pollen viability

\subsubsection{Materials and methods}

Eleventomato hybrids are screened (Mass scale screening) for heat at early seedling stage. Two replications are kept for each hybrid. 15 seedlings are maintained for each replication. Seedlings are grown up to 30 days at $45-47^{\circ} \mathrm{C}$ temperature (during this experiment maximum recorded temperature was $45-47^{0} \mathrm{C}$ temperature). This condition offers heat stress at seedling stage which leads maximum stress on seedling survival, establishment and growth in small pots. Percentage of seedling survival under heat stress condition has taken into consideration for selecting heat tolerant hybrids. Pollen viability of 3 tomato lines was conducted by using Iodine Potassium Iodide (IKI) staining method.

\subsubsection{Results and discussion}

- Hybrids showing 90 to $100 \%$ of seeding survival is selected for heat tolerance at seedling stage. 4 hybrids are selected for heat tolerance.

- There is large genotypic variation is observed in seedling survival ranging from 0 to $100 \%$ exposed to heat stress.

- During flowering time, maximum temperature is recorded 45 to $47^{\circ} \mathrm{C}$. Four hybrids were selected showing $50 \%-58 \%$ of pollen viability.

- Four hybrids- TH-102, TH-103, TH-110 and TH- 111 are showing $90-100 \%$ of seedling survival after completion of 30 days period under $45-47^{\circ} \mathrm{C}$ temperature.

\subsubsection{Conclusion}

Percentage of seedling survival under stress condition has taken into consideration for selecting heat hybrids showing 90 to $100 \%$ of seeding survival are selected for Heat tolerant at seedling stage. 4 hybrids are selected for heat tolerance. These hybrids may be recommended for growing under heat and drought stress prone areas for better adaptation.

\subsubsection{Screening of chilli lines for heat stress tolerance}

Two experiments were conducted for heat stress tolerance at the seedling stage and another for pollen viability (Figure 15-16).

2.2.3.1. Screening of chilli lines for heat stress tolerance at vegetative stage 
Twelve chilli lines were tested for heat tolerance at vegetative stage. 30 days old Seedlings were transplanted to medium size plastic pots. 40 days plants exposed to heat stress (38$42^{0} \mathrm{C}$ temperature). Severe leaf burnt was observed in heat susceptible lines.

\subsubsection{Effect of heat stress on pollen viability of chilli}
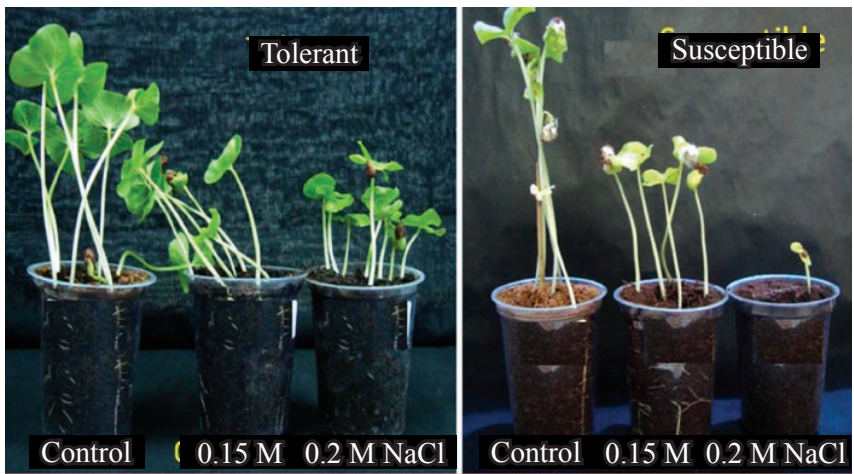

Figure 1: Variability in response to salinity stress at seedling stage- salinity tolerant entry TH-10 showing higher seedling emergence compared to salinity susceptible entry 3027 under $0.15 \mathrm{M} \& 0.2 \mathrm{M} \mathrm{NaCl}$.

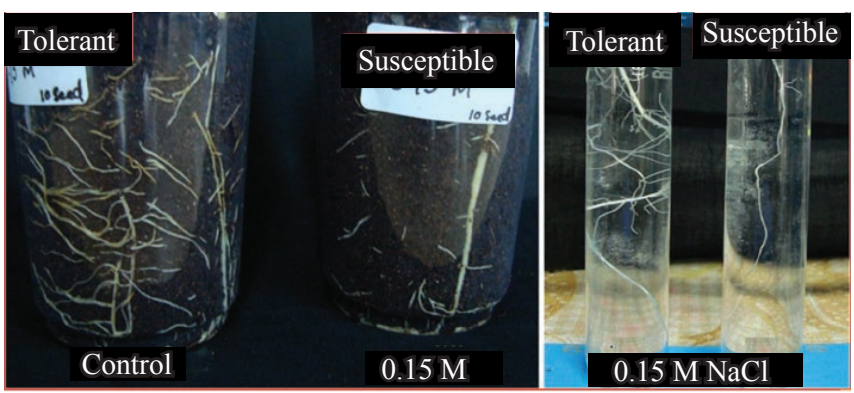

Figure 2: Variability in root density in salinity tolerant (TH10) and susceptible (3009) entries- Higher number and longer lateral roots was noticed in tolerant line.
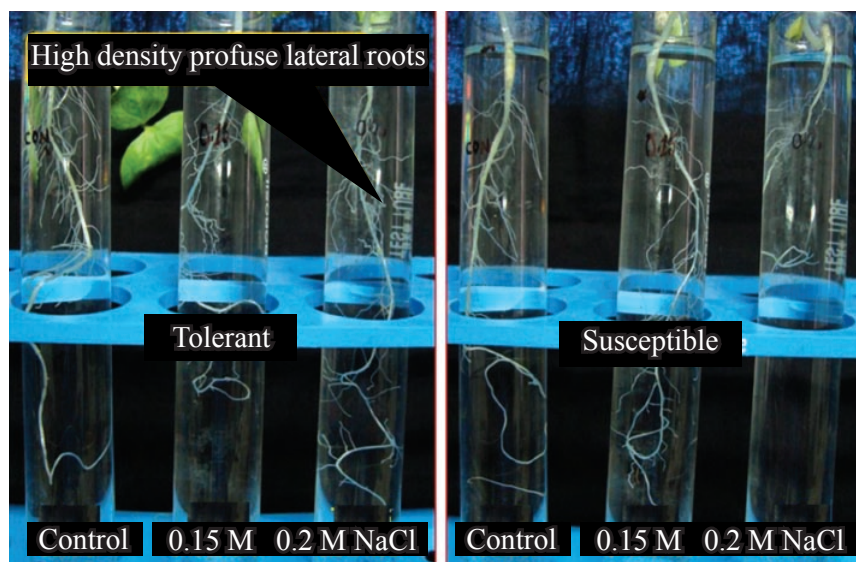

Figure 3: Salinity tolerant entry showing more number of profuse lateral roots in 0.15 and $0.2 \mathrm{M} \mathrm{NaCl}$ compared to susceptible entry. genotypes

Eighty-three chilli lines were observed for pollen viability. Flowers collected form plants grown in RBF. From each line 5 flowers are selected. Anthers squeezed and stained with Iodine potassium iodide. 10 readings were taken for each flower. Most of the lines showed very less pollen viability.
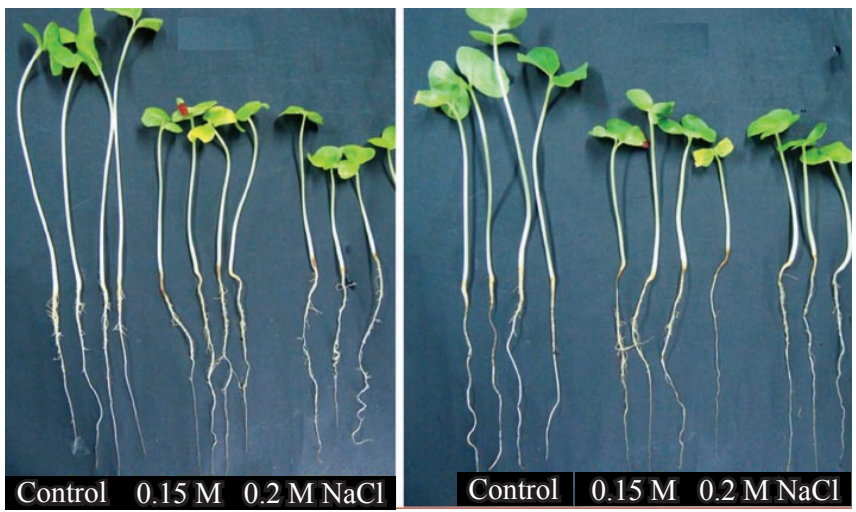

Figure 4: Response of root length-two hybrids showing fine profuse lateral roots under saline conditions

Emergence and seedling vigour in control \& $0.15 \mathrm{M} \mathrm{Nacl}$ (13.6 E.C.)

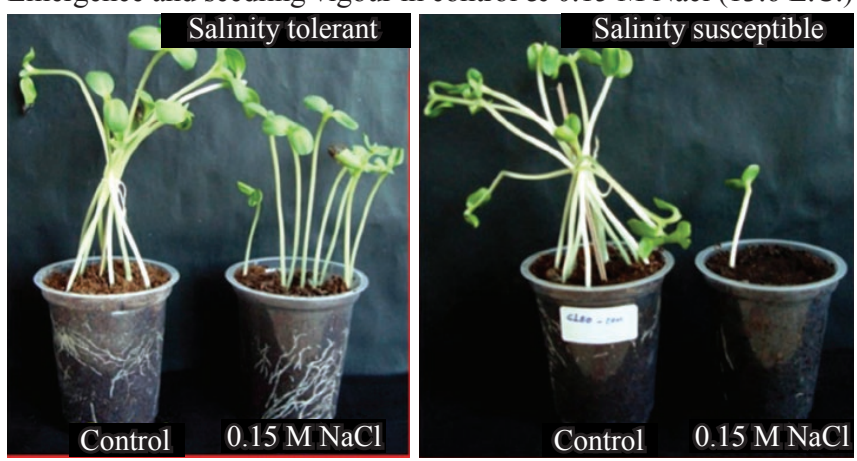

Figure 5: Tolerant line showing good emergence at $0.15 \mathrm{M}$ $\mathrm{NaCl}$ (13.6 E.C.) compared to susceptible line

Variation in root length of tolerant \& susceptible hybrids at control \& .15M

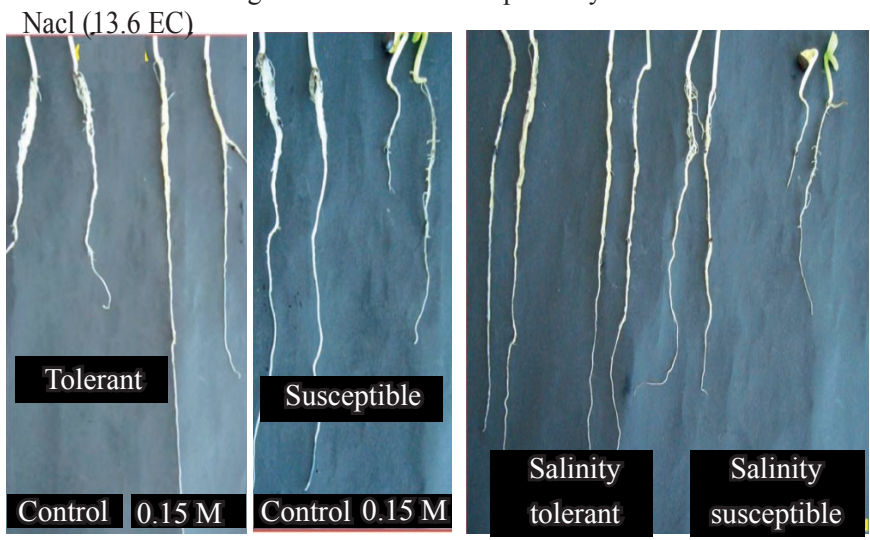

Figure 6: Tolerant hybrid showing increased roots length under saline conditions compared with control and also showing more number of fine lateral roots. Susceptible hybrid showing decreased roo t length. 


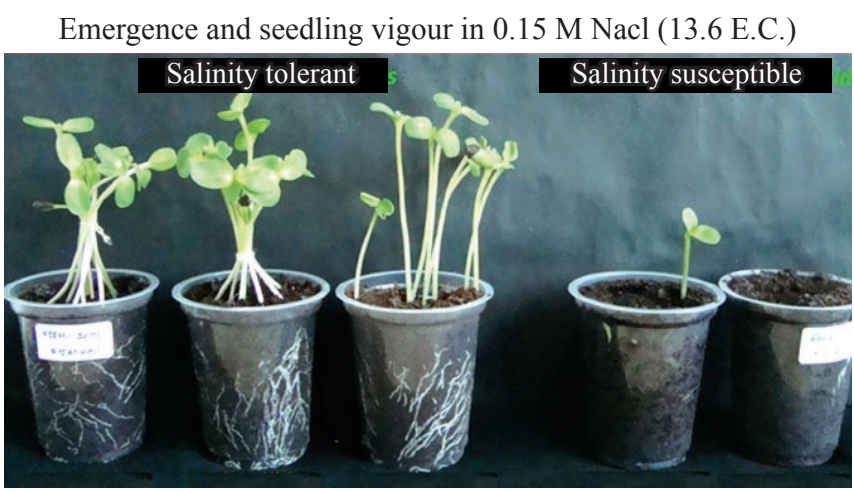

Figure 7: Effect of salinity $0.15 \mathrm{M} \mathrm{NaCl}$, (13.6 E.C.) on growth pattern of salinity tolerant hybrids \& susceptible hybrids

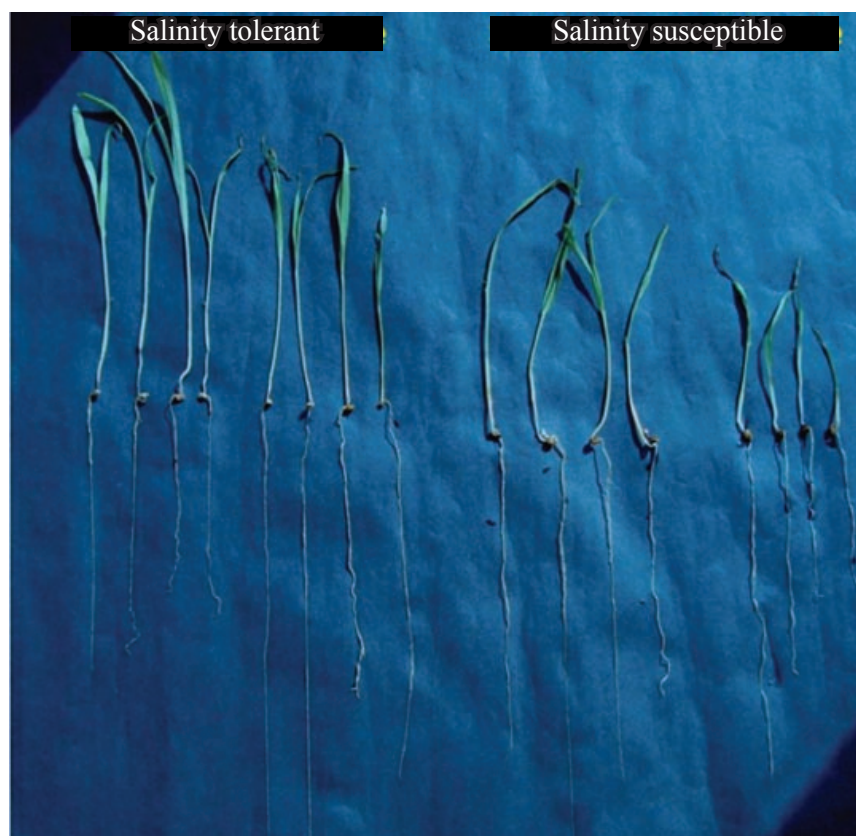

Figure 8: Salinity tolerant line showing less soot length and higher root length under $0.15 \mathrm{M} \mathrm{NaCl}$ compared to susceptible line

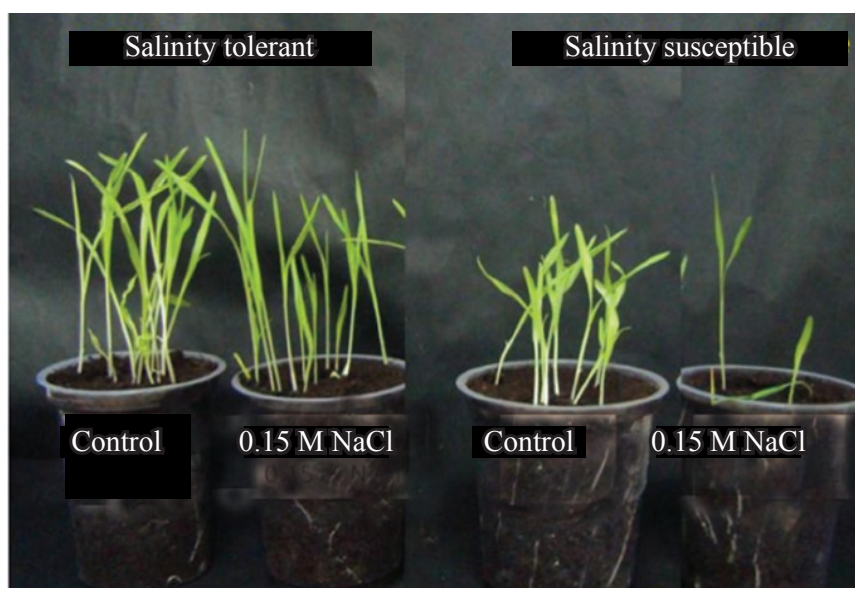

Figure 9: Under saline condition, salinity tolerant line showing higher seedling emergence compared to salinity susceptible line
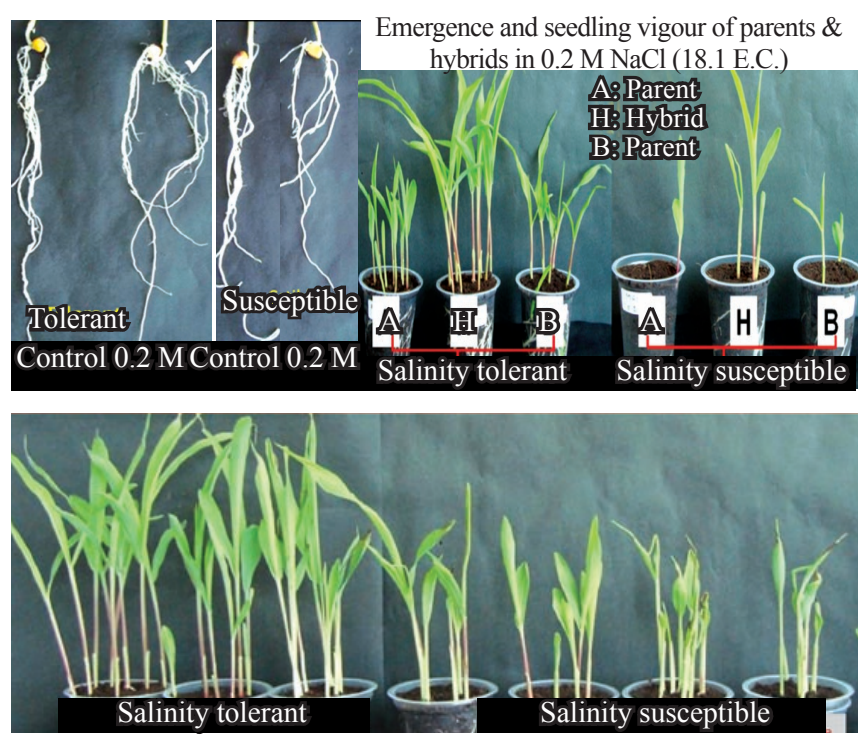

Figure 10: Effect of salinity stress on root growth, seedling emergence and seedling vigour of toleran and susceptible parents and hybrids in maize

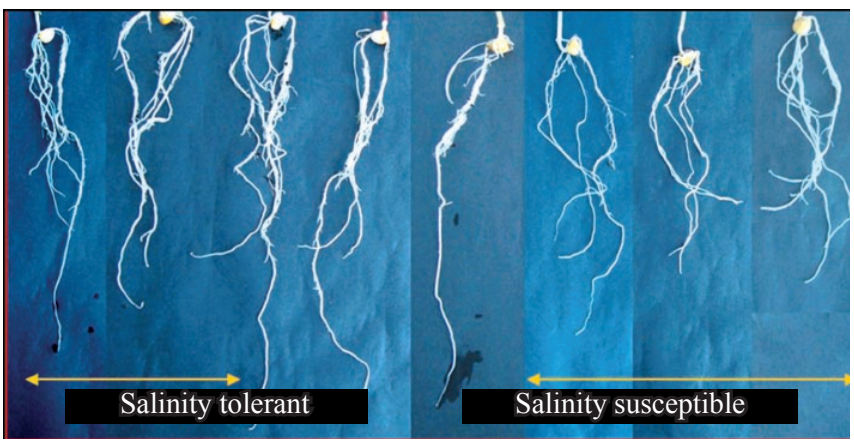

Figure 11: Variability and root vigour among different hybrids under $0.2 \mathrm{M} \mathrm{NaCl}$

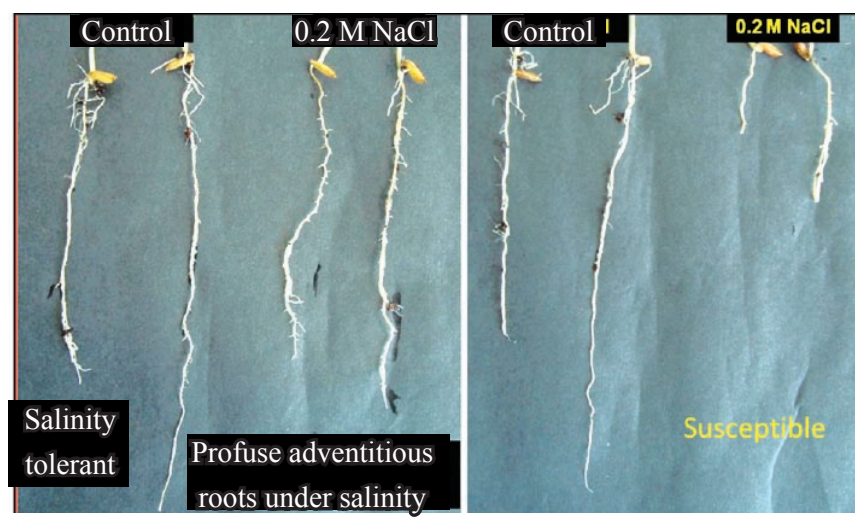

Figure 12: Salinity tolerant variety producing profuse adventitious roots under saline condition (for osmotic adjustment) compared to susceptible variety

\subsection{Screening of castor hybrids for drought tolerance}

Two experiments were conducted for drought and heat stress tolerance (Figure 17-18). 

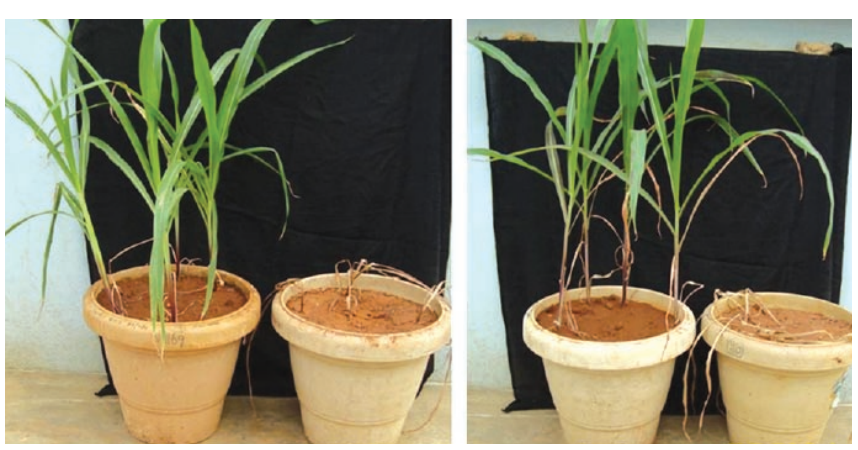

Figure 13: Response of Maize seedlings to heat stress. Seedlings of tolerant genotypes are not showing any significant effect of heat stress. In the contrary, susceptible hybrids showed completely dried seedlings.
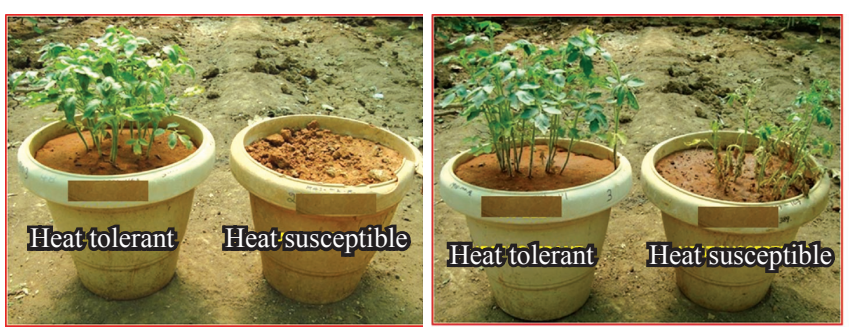

Figure 14: Response of Tomato seedlings to heat stress. Seedlings of tolerant hybrids are not showing any significant effect of heat stress. In the contrary, susceptible hybrids showed dried seedlings $(0 \%-13 \%$ of seedling survival)
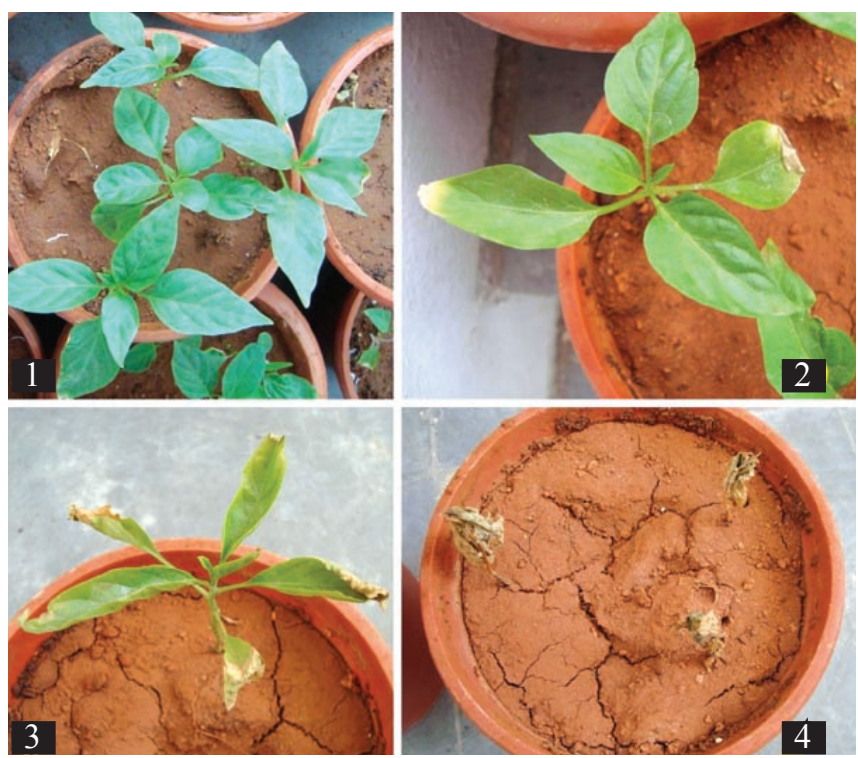

Figure 15: Variability in response to heat stress at vegetative stage. 1) Heat tolerant line 2), $3 \& 4$ ) Heat susceptible lines

\subsubsection{Screening of castor hybrids for drought tolerance}

\subsubsection{Materials and methods}

11 castor hybrids were screened for drought resistance in

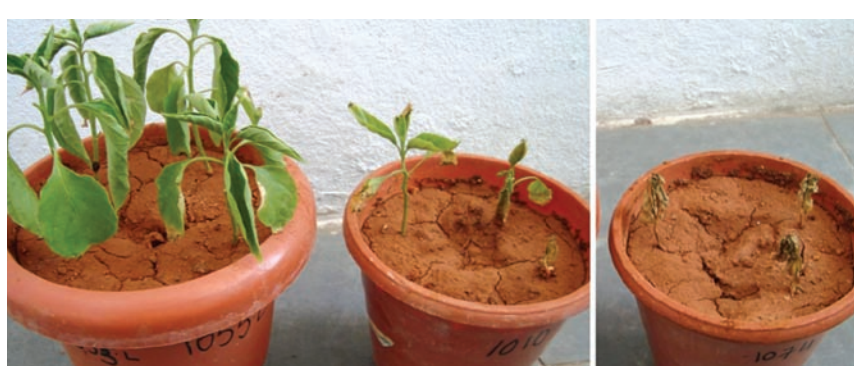

Figure 16: Variability in response to heat stress at vegetative stage. Tolerant line showing wilting but 1010 showing severe leaf burnt and 1074 completely died

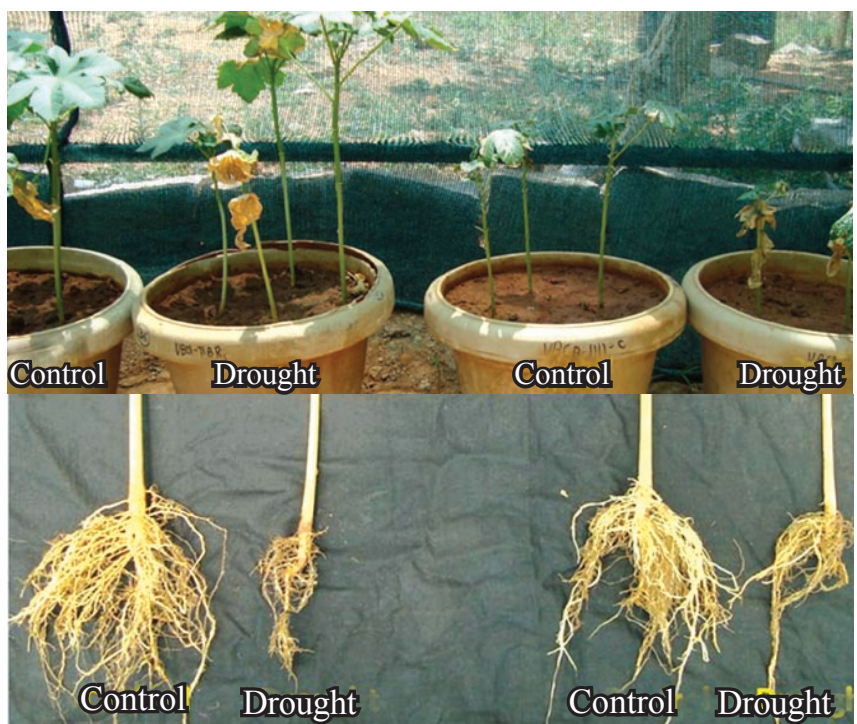

Figure 17: Drought resistant line showing better growth compared to susceptible line

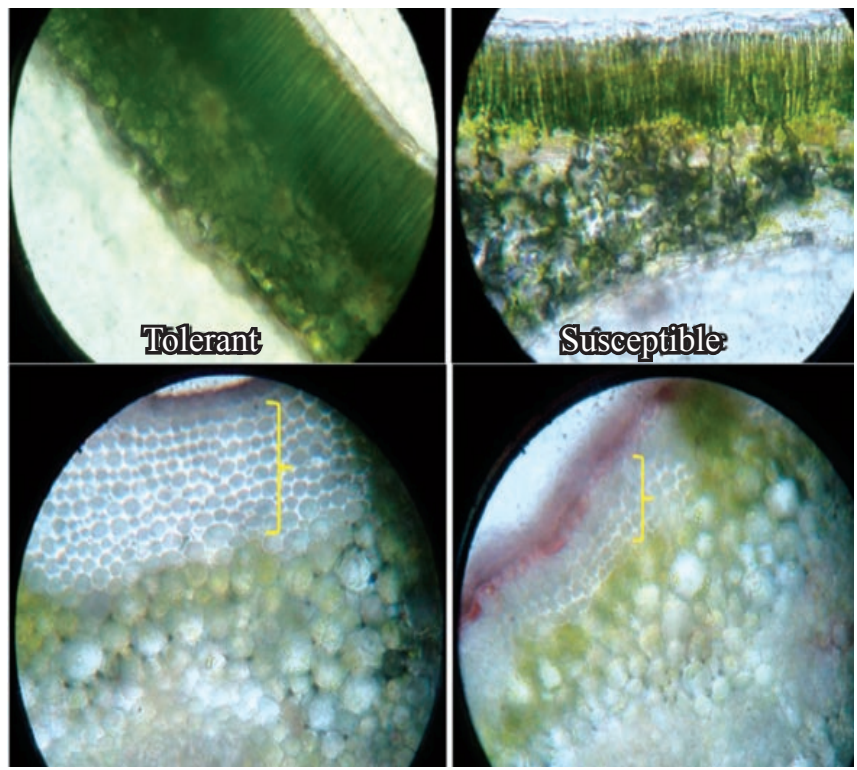

Figure 18: leaf transverse sections of tolerant and susceptible lines. Tolerant line has thick compactly arranged palisade tissue and higher number of collenchyma layers compared to susceptible line 
poly house at 30 days after seedling emergence. Applied 3 drought cycles with gradually increasing the stress period viz., $1^{\text {st }}$ Drought cycle 10 days, $2^{\text {nd }}$ drought cycle 15 and $3^{\text {rd }}$ drought cycle 25 days period. Lot of variability was observed among the hybrids with respect to plant survival, wilting, and recovery from drought period and root length. Hybrids having morphologically thick leaves with stout petiole has shown less wilting. Leaf and petiole thickness also observed for drought resistance. Number of collenchymas layers also varied among the lines. Thick compactly arranged collenchymas tissue in leaves reduces traspirational loss of water from leaves. Hybrids are selected after recovery: after each drought cycle, hybrids allowed for 2 days of recovery period and minimum leaf burnt and wilting with good recovery after $3^{\text {rd }}$ drought cycle.

\subsubsection{Conclusion}

From this study hybrids with thick leaves, stout petiole, good survival under drought and recovery from stress are considered for selecting drought resistant hybrids in castor.

\section{References}

Maiti, R.K., 2012. Editorial: Root responses are indicators for salt tolerance and drought stress in Crops. International Journal of Bio-resource and Stress Management 3(3), i-iii.

Maiti, R.K., 2012. Editorial: Low cost technology for increasing crop productivity under sustainable agriculture. International Journal of Bio-resource and Stress
Management 3(4), i-iii.

Maiti, R.K., 2012. A novel strategy to improve crop productivity under sustainable agriculture. International Journal of Bio-resource and Stress Management 3(2), 128-138.

Maiti, R.K., Rodriguez, H.G., Rajkumar, D., Kausik, S., Vidyasagar, P., 2012. Genotypic variability in salinity tolerance of maize pipe line hybrids at the seedling stage. International Journal of Bio-resource and Stress Management 3(4), 427-432.

Maiti, R.K., Rajkumar, D., Vidyasagar, P., 2012. Screening of rice varieties for drought resistance at the seedling stage. Research on Crops 13(3), 790-794.

Maiti, R.K., Satya, P., 2011. Editorial: Revisiting the role of physiology and biochemistry in salt tolerant genotype development. International Journal of Bio-resource and Stress Management 3(1), i-ii.

Maiti, R.K., Satya, P., 2013. Editorial: Phenomics for abiotic stress tolerance: Challenges ahead. International Journal of Bio-resource and Stress Management 4(1), i-iv.

Sarkar, N.C., Mandal, B., Rajkumar, D., Maiti, R.K., 2012. Salt tolerance of thirteen rice (Oryza sativa L.) varieties at germination and seedling stage. Research on Crops 13(3), 795-803.

Satya, P., Maiti, R.K., 2011. Molecular breeding for mitigation of abiotic stress scenario: Potentials and limitations for developing and underdeveloped countries. International Journal of Bio-resource and Stress Management 2(1), i-v. 